\title{
Patient safety culture in Jordanian primary health-care centres as perceived by nurses: a cross-sectional study
}

Abdullah Khamaiseh, ${ }^{1}$ Diala Al-Twalbeh ${ }^{2}$ and Kamel Al-Ajlouni ${ }^{3}$

${ }^{1}$ Department of Community and Mental Health Nursing, Faculty of Nursing, Mutah University, Mutah, Jordan (Correspondence to: A. Khamaiseh: akhamaiseh@mutah.edu.jo; abdullahkhamaiseh@yahoo.com). ${ }^{2}$ Department of Medical Support, Al-Balqa Applied University, Karak, Jordan. ${ }^{3}$ Director of Nursing Directorate, Ministry of Health, Amman, Jordan.

\begin{abstract}
Background: Patient safety is a major concern, both in hospitals and primary care settings. The Jordan Medical Association has recommended that all health-care centres should try to improve patient safety through improving organizational culture, as it is in hospitals. In Jordan, a survey of patient safety culture has not yet been fully implemented in primary health-care centres.

Aims: To determine attitudes of nurses regarding patient safety culture in primary health-care centres in Jordan.

Methods: A cross-sectional descriptive study was conducted in 2017. Data were collected from 644 nurses working in all 91 accredited primary health-care centres in Jordan, based on the Safety Attitudes Questionnaire short form 36-item version.

Results: The average positive response rate to the 6 domains of safety culture ranged from $58.54 \%$ to $75.63 \%$. The highest average positive response rate was for job satisfaction and the lowest was for perceptions of management.

Conclusions: The areas that need improvement from nurses' perception are: teamwork climate, safety climate, stress recognition, and perception of management. Jordanian primary health-care nurses perceive their health centres as places that need more effort to improve safety culture.

Keywords: patient safety culture, safety attitudes questionnaire, nurses, primary health-care centres, Jordan

Citation: Khamaiseh A; Al-Twalbeh D; Al-Ajlouni K. Patient safety culture in Jordanian primary health-care centres as perceived by nurses: a cross-sectional study. East Mediterr Health J. 2020;26(10):1242-1250. https://doi.org/10.26719/emhj.20.044

Received: 10/03/19; accepted: 11/09/19

Copyright (C) World Health Organization (WHO) 2020. Open Access. Some rights reserved. This work is available under the CC BY-NC-SA 3.0 IGO license (https://creativecommons.org/licenses/by-nc-sa/3.o/igo)
\end{abstract}

\section{Introduction}

The World Health Organization (WHO) has proposed patient safety as a fundamental concept in the provision of care services (1). Due to unsafe medical care, millions of patients worldwide suffer from disabilities, injuries or death every year (2-4). Patient safety is a major concern, both in hospitals and in primary care settings (5). Safety in healthcare has therefore received substantial attention worldwide since the late 1990 s $(6,7)$. Patient safety is defined as "the prevention of harm caused by errors of commission and omission" (8). The Jordan Medical Association has recommended that all healthcare centres should try to improve patient safety through improving organizational culture, as it is in hospitals (9). The organizational structure is described as the common values, beliefs, behaviours, perceptions and attitudes of the staff in a healthcare centre (6-8,10-12).

A growing body of evidence indicates that the rate of medical errors and adverse events is associated with the attitudes of healthcare professionals towards safety (13). Nurses play a vital role in maintaining and promoting patient safety due to the nature of their work (14); being the frontline care providers, and spending more of their time in direct patient care activities than any other health professionals (15). The term safety culture is often used interchangeably with safety climate and occasionally with attitudes toward safety (16).

Like elsewhere, the healthcare system in Jordan mainly consists of the public/semipublic sector and the private sector; each of which includes hospitals, primary care clinics, pharmacies, and other ancillary services. A total of 106 hospitals in Jordan, providing 12081 beds, are now distributed disproportionately in the 2 sectors. The public sector accounts for the majority of hospital beds (67\%) and private hospitals provide the remainder (33\%). Overall, there are about 18 beds per 10 ooo people. The development of protocols and guidelines for workers and the formation of committees to fight infection and improve the quality of service provision in hospitals are some of the immediate gains of such programmes. This means that the Ministry has institutionalized the process of quality improvement in health centres and hospitals in order to improve the quality of health services (17). In a study conducted in Jordan, Hayajneh et al. (18) found that $28 \%$ of all hospital admissions were affected by medical errors and the main types of error were: medication errors, wrong diagnosis, hospital-acquired infection, bed sores and patient falls.

It is probably axiomatic that patient safety is a primary concern in primary care settings. However, to date, most patient safety research has focused on hospital care. The 
goal of such research has mainly been to measure and strengthen safety culture in hospitals $(5,15,19)$. Research on how to improve patient safety in primary care still awaits further verification (20).

In Jordan, a survey of patient safety culture has not yet been fully implemented in primary health centres. Therefore, the main aim of this study was to determine attitudes of nurses regarding patient safety culture in primary healthcare centres in Jordan, based on the Safety Attitudes Questionnaire (SAQ).

\section{Methods}

\section{Study design and setting}

This was a cross-sectional descriptive study. The Jordanian Ministry of Health has 91 accredited primary healthcare centres distributed in 12 governorates. Data were collected from all of these centres between September and October 2017.

\section{Study participants}

The study participants included all nurses who were willing to participate in the study at the time of data collection. The participants were selected based on the following criteria: being registered; associated or assistant nurse; having at least 1 year of experience in governmental health settings; having worked in the concerned centre for a minimum of 6 months; having Jordanian nationality; and giving signed informed consent. Accordingly, there were 286 registered nurses, 240 assistant nurses, and 118 associated nurses, with a total of 644 participants.

\section{Data collection instrument}

Data were collected by distributing a self-administered structured questionnaire that consisted of 2 parts. In Part 1, the demographic data of the participant nurses were collected. Part 2 comprised the Safety Attitudes Questionnaire (SAQ) short-form 36-item version. It is worth noting that this questionnaire has been used worldwide to evaluate nurses' awareness about patient safety culture. It is one of the tools most used to evaluate the safety culture through which healthcare is provided and used to investigate the relationship between the safety culture in healthcare and patient outcomes (21).

The SAQ allowed assessment of the perceptions and attitudes of health professionals related to patient safety in several clinical areas and health services, and was validated in a sample of 10843 healthcare providers in 203 clinical areas, including intensive care units, operating theatres, inpatient units and outpatient clinics. The full version of the questionnaire includes 60 items, of which only 30 are standard and identical in all clinical settings. These 30 basic items made up the short version reviewed in this study (SAQ - Short Form), to which other items were added to provide a total of 36 . The instrument measured perceptions of the healthcare professionals in 6 areas: teamwork climate (Items 1-6); safety climate (Items 7-13); job satisfaction (Items 15-19); stress recognition (Items 20-23); perception of management (Items 24-29) and working conditions (Items 30-32). Items 14 and 3336 were not part of the dimensions referred to above, and Items 2, 11 and 36 were written in reverse.

The answers to each question followed a 5-level Likert scale: A - strongly disagree, B -slightly disagree, C - neutral, D - slightly agree, E - strongly agree and $\mathrm{X}$ - not applicable. The final score ranged from $\mathrm{O}$ to 100 , where 0 represented the worst and 100 the best perception (22). Results were converted from categorical to continuous variables as follows: strongly disagree $=$ 0 ; slightly disagree $=25$; neutral $=50$; slightly agree $=$ 75 ; and strongly agree $=100$. A not applicable response was excluded from the scoring. Some items were reverse scored so that a higher score always represented a more positive attitude. For each respondent, a mean score of $\geq 75$ for the items in a particular dimension indicated a positive safety attitude for that dimension (23).

\section{Validity and reliability of the questionnaire}

The questionnaire was translated into Arabic and was pilot tested on 60 nurses (registered, assistant and associated) from different primary healthcare centres. Reliability of the whole questionnaire was measured by Cronbach's $\alpha 0.9$

\section{Data collection}

Prior to commencing data collection, nurse managers in each selected accredited primary healthcare centre were informed of the research and all relevant issues were discussed. Copies of the questionnaire, information sheet, ethical approval letters and consent forms were made available to them. Prior to commencing the survey, 24 research assistants were hired to help the researchers conduct the study. The research assistants' role was to distribute the questionnaires and clarify the questions. They also offered assistance to potential participants who needed help in completing the questionnaires. Finally, the research assistants' collected the completed questionnaire and returned them to the researchers. Duration of data collection was from September to October 2017.

\section{Ethical considerations}

This study was conducted in compliance with the ethical guidelines of Mutah University, so all participants received written consent about the purpose of the study, especially that the data were collected anonymously and treated with utmost confidentiality. We received permission to use the short form of the SAQ from the Centre for Health Care Quality \& Safety. Prior to data collection, official approval to conduct this study was obtained from the Research and Ethics Committee at the Faculty of Nursing at Mutah University. Approval to conduct the study was obtained from the Ministry of Health. Participation in this study was voluntary. Participating nurses were asked to submit their formal written and informal verbal consents. 


\section{Statistical analysis}

Data analysis was performed using IBM SPSS Statistics for Windows, version 21.0 (IBM, Armonk, NY, USA). Descriptive statistics using frequencies, percentages, means and standard deviation were calculated to describe the participants' demographic characteristics and inferential statistics using analysis of variance and $t$ tests to compare subscale dimensions with $P<0.05$ indicating statistical significance.

\section{Results}

\section{Part 1: participants characteristics}

Table 1 displays the demographic information of the 644 nurses who participated in the study. Most of the participants were female $(n=552 ; 85.7 \%)$, aged $31-40$ years $(n=300 ; 46.6 \%)$, married $(n=437 ; 67.9 \%)$, educated to diploma level $(n=363 ; 56.3 \%)$, and registered nurses $(n=$ $286 ; 44.4 \%)$. Finally, most of them $(n=495 ; 76.9 \%)$ had worked at a primary healthcare centre for $\geq 5$ years.

\section{Part 2: Survey results}

Table 2 shows the average score obtained for each domain according to sex, age, job position, educational level, job experience and unit of work. Female nurses had better scores for patient safety attitude than male nurses had in all domains except stress recognition. No significant difference in the perception of patient safety was found between male and female nurses. Job satisfaction and working conditions were the domains with values > 75 (positive safety attitude) among female nurses.

All age categories had positive attitudes regarding job satisfaction and working conditions (Table 2). Assistant nurses had the highest positive score regarding job satisfaction, while associated nurses had the highest positive score regarding working conditions. Positive scores were obtained among those educated to diploma and bachelor's degree level for job satisfaction and working conditions (Figure 1).

The highest positive safety score $(78.10 \%)$ toward job satisfaction was among nurses who had $>20$ years' work experience, while the highest positive score toward working conditions was among nurses who had 11-15 years' experience (Table 2). Nurses working in accident and emergency, or maternal and child health had positive safety attitudes regarding job satisfaction and working conditions. Psychiatric unit nurses had a positive attitude toward working conditions, and dental unit nurses had a positive attitude toward job satisfaction.

Table 3 shows the distribution of the nurses' answers per item of the scale.

Regarding teamwork climate, almost two fifths of nurses expressed that it was difficult to speak openly when they perceived a problem related to patient care. Two thirds of them confirmed that disagreements in their clinical area were resolved appropriately and almost three quarters stated that it was easy for personnel to ask questions when there was something that they did

\begin{tabular}{|c|c|c|}
\hline Variable & No. & $\%$ \\
\hline \multicolumn{3}{|l|}{ Sex } \\
\hline Male & 92 & 14.3 \\
\hline Female & 552 & 85.7 \\
\hline \multicolumn{3}{|l|}{ Age, $y r$} \\
\hline $20-30$ & 181 & 28.1 \\
\hline $31-40$ & 300 & 46.6 \\
\hline $41-50$ & 136 & 21.1 \\
\hline$>50$ & 27 & 4.2 \\
\hline \multicolumn{3}{|l|}{ Marital status } \\
\hline Single & 90 & 14.0 \\
\hline Married & 437 & 67.9 \\
\hline Separated & 109 & 16.9 \\
\hline Divorced & 8 & 1.2 \\
\hline \multicolumn{3}{|l|}{ Education level } \\
\hline Diploma & 363 & 56.3 \\
\hline Bachelor & 259 & 40.2 \\
\hline Master & 21 & 3.3 \\
\hline $\mathrm{PhD}$ & 1 & .2 \\
\hline \multicolumn{3}{|l|}{ Job positions } \\
\hline Registered nurse & 286 & 44.4 \\
\hline Associated nurse & 118 & 18.3 \\
\hline Assistant nurse & 240 & 37.3 \\
\hline \multicolumn{3}{|l|}{ Unit } \\
\hline General clinic & 166 & 25.8 \\
\hline Accident \& emergency & 208 & 32.3 \\
\hline Maternity \& child care & 177 & 27.5 \\
\hline Psychiatry & 17 & 2.6 \\
\hline Dental & 76 & 11.8 \\
\hline \multicolumn{3}{|l|}{ Job experience, yr } \\
\hline $1-5$ & 149 & 23.1 \\
\hline $6-10$ & 154 & 23.9 \\
\hline $11-15$ & 150 & 23.3 \\
\hline $16-20$ & 88 & 13.7 \\
\hline$\geq 20$ & 103 & 16.0 \\
\hline
\end{tabular}

not understand. Most of them (80.4\%) answered that the physicians and nurses worked together as a wellcoordinated team.

Regarding safety climate, three quarters of participants would feel safe being treated as a patient at their clinics, and medical errors were handled appropriately in this clinical area. A total of $68.9 \%$ confirmed that they knew the proper channels to direct questions regarding patient safety, whereas $36.3 \%$ stated that it was difficult to discuss errors in this clinical area. However, $68.6 \%$ responded that they were encouraged by their colleagues to report any patient safety concerns, and $76.1 \%$ stated that the culture in this clinical area made it easy for them to learn from the errors of others. 


\begin{tabular}{|c|c|c|c|c|c|c|}
\hline $\begin{array}{l}\text { Characteristics, } \\
\text { mean (SD) }\end{array}$ & $\begin{array}{l}\text { Teamwork } \\
\text { climate }\end{array}$ & Safety climate & Job satisfaction & $\begin{array}{c}\text { Stress } \\
\text { recognition }\end{array}$ & $\begin{array}{c}\text { Perceptions of } \\
\text { management }\end{array}$ & $\begin{array}{l}\text { Working } \\
\text { conditions }\end{array}$ \\
\hline \multicolumn{7}{|l|}{ Sex } \\
\hline Male & $65.26(17.55)$ & $62.24(15.62)$ & $73.36(16.30)$ & $64.80(26.96)$ & $56.81(21.0)$ & $74.86(18.01)$ \\
\hline Female & $66.17(15.68)$ & $64.97(15.22)$ & $76.0(16.10)$ & $61.6(24.76)$ & $58.83(21.19)$ & $75.34(17.92)$ \\
\hline $\mathrm{t}$ & -0.508 & -1.577 & -1.453 & 1.130 & -0.842 & -0.2361 \\
\hline $\mathrm{P}$ & 0.611 & 0.115 & 0.147 & 0.259 & 0.40 & 0.814 \\
\hline \multicolumn{7}{|l|}{ Age, yr } \\
\hline $20-30$ & $65.35(17.88)$ & $63.91(15.25)$ & 75.46 (16.92) & $65.15(26.32)$ & $59.50(20.62)$ & $75.44(18.37)$ \\
\hline $31-40$ & $65.58(15.02)$ & $64.19(14.68)$ & $74.18(14.70)$ & $62.16(24.0)$ & $57.62(20.52)$ & $74.47(18.06)$ \\
\hline $41-50$ & $68.19(14.46)$ & $66.66(15.42)$ & $78.22(18.42)$ & $59.19(25.19)$ & $58.39(23.53)$ & $76.94(16.38)$ \\
\hline$>50$ & $64.96(19.06)$ & $63.04(21.04)$ & $79.81(11.64)$ & $54.86(26.30)$ & $62.96(19.72)$ & $74.53(21.01)$ \\
\hline $\mathrm{F}$ & 1.064 & 1.104 & 2.593 & 2.268 & 0.703 & 0.607 \\
\hline$P$ & 0.364 & 0.347 & 0.052 & 0.079 & 0.550 & 0.611 \\
\hline \multicolumn{7}{|l|}{ Job positions } \\
\hline Registered nurse & $64.81(16.86)$ & $63.48(15.19)$ & $74.64(15.87)$ & $61.40(25.15)$ & $57.94(20.89)$ & $75.04(18.35)$ \\
\hline Associated nurse & $68.75(11.81)$ & $65.92(13.66)$ & $74.83(15.28)$ & $65.41(23.63)$ & $63.60(17.60)$ & $76.32(14.93)$ \\
\hline Assistant nurse & $66.18(16.47)$ & $65.24(16.15)$ & $77.19(16.79)$ & $61.22(25.68)$ & $56.82(22.72)$ & $75.02(18.78)$ \\
\hline $\mathrm{F}$ & 2.56 & 1.41 & 1.80 & 1.28 & 4.23 & 0.248 \\
\hline$P$ & 0.078 & 0.245 & 0.166 & 0.278 & 0.015 & 0.780 \\
\hline \multicolumn{7}{|l|}{ Educational level } \\
\hline Diploma & $66.65(15.78)$ & $65.92(14.92)$ & $75.84(16.77)$ & $62.10(25.49)$ & $58.52(21.64)$ & $74.89(18.80)$ \\
\hline Bachelor's & $65.68(15.98)$ & 63.49 (14.93) & $75.56(14.47)$ & $62.83(24.69)$ & $59.65(19.40)$ & $76.18(16.12)$ \\
\hline Master's & 60.91 (17.89) & $55.61(21.82)$ & $74.76(22.27)$ & $51.78(22.37)$ & $45.23(29.55($ & $70.83(23.32)$ \\
\hline $\mathrm{PhD}$ & 45.83 & 50.00 & 35.00 & 68.75 & 60.00 & 68.75 \\
\hline $\mathrm{F}$ & 1.485 & 4.127 & 2.166 & 1.282 & 3.030 & 0.749 \\
\hline$P$ & 0.218 & 0.007 & 0.091 & 0.280 & 0.029 & 0.523 \\
\hline \multicolumn{7}{|l|}{ Job experience, yr } \\
\hline $1-5$ & $66.07(17.25)$ & $63.87(16.38)$ & $73.98(17.72)$ & $61.36(26.51)$ & $58.69(22.31)$ & $75.58(20.06)$ \\
\hline $6-10$ & $65.55(16.30)$ & $63.56(14.91)$ & $76.30(13.64)$ & $65.01(25.83)$ & $58.62(20.20)$ & $74.51(17.30)$ \\
\hline $11-15$ & $67.44(14.28)$ & $64.42(14.57)$ & $74.96(15.66)$ & $63.87(22.91)$ & $60.30(18.53)$ & 78.12 (13.0) \\
\hline $16-20$ & $63.82(15.14)$ & $65.58(14.17)$ & $75.45(15.84)$ & $59.01(25.61)$ & $57.70(21.29)$ & $70.83(21.87)$ \\
\hline$>20$ & 66.58 (16.49) & $66.54(16.27)$ & $78.10(17.98)$ & $58.67(24.14)$ & $56.30(24.42$ & $75.54(17.59)$ \\
\hline $\mathrm{F}$ & 0.779 & 0.762 & 1.124 & 1.555 & 0.574 & 2.390 \\
\hline$P$ & 0.539 & 0.550 & 0.344 & 0.185 & 0.682 & 0.050 \\
\hline \multicolumn{7}{|l|}{ Unit } \\
\hline General clinic & $64.58(16.24)$ & 61.68 (15.99) & $74.51(18.31)$ & $64.42(25.50)$ & $58.30(20.92)$ & $73.37(18.49)$ \\
\hline$A \& E$ & $68.12(15.14)$ & $65.76(14.02)$ & 76.64 (15.03) & $61.74(24.96)$ & $58.36(21.24)$ & $76.41(16.42)$ \\
\hline $\mathrm{MCH}$ & $65.53(16.66)$ & $65.48(15.61)$ & $75.90(15.46)$ & $58.12(26.06)$ & $58.62(20.78)$ & $76.55(18.69)$ \\
\hline Psychiatry & $68.13(12.66)$ & $64.70(11.83)$ & $72.05(13.46)$ & $66.54(20.72)$ & 64.68 (12.17) & $76.83(9.57)$ \\
\hline Dental & $64.25(16.13)$ & $65.55(16.56)$ & $75.46(16.23)$ & $66.03(22.20)$ & $58.06(24.03)$ & $72.94(19.93)$ \\
\hline $\mathrm{F}$ & 1.599 & 2.027 & 0.622 & 2.092 & 0.355 & 1.255 \\
\hline $\mathrm{P}$ & 0.173 & 0.089 & 0.647 & 0.080 & 0.841 & 0.286 \\
\hline
\end{tabular}

$\mathrm{A \& E}=$ accident and emergency; $\mathrm{MCH}=$ maternal and child health; $S \mathrm{D}=$ standard deviation .

Regarding job satisfaction, almost three quarters of participants stated that they liked their job, with responses such as "working here is like being part of a large family"; "this is a good place to work in", "we are proud to work in this clinical area", and "the morale in this clinical area is high".
In the domain of stress recognition, $68.2 \%$ of participants confessed that they were less effective at work when fatigued, and 59.3\% were more likely to make errors in tense or hostile situations.

In relation to perceptions of management, $62.6 \%$ of the nurses answered that management did not knowingly 
Figure 1 Educational levels in relation to patient safety domains

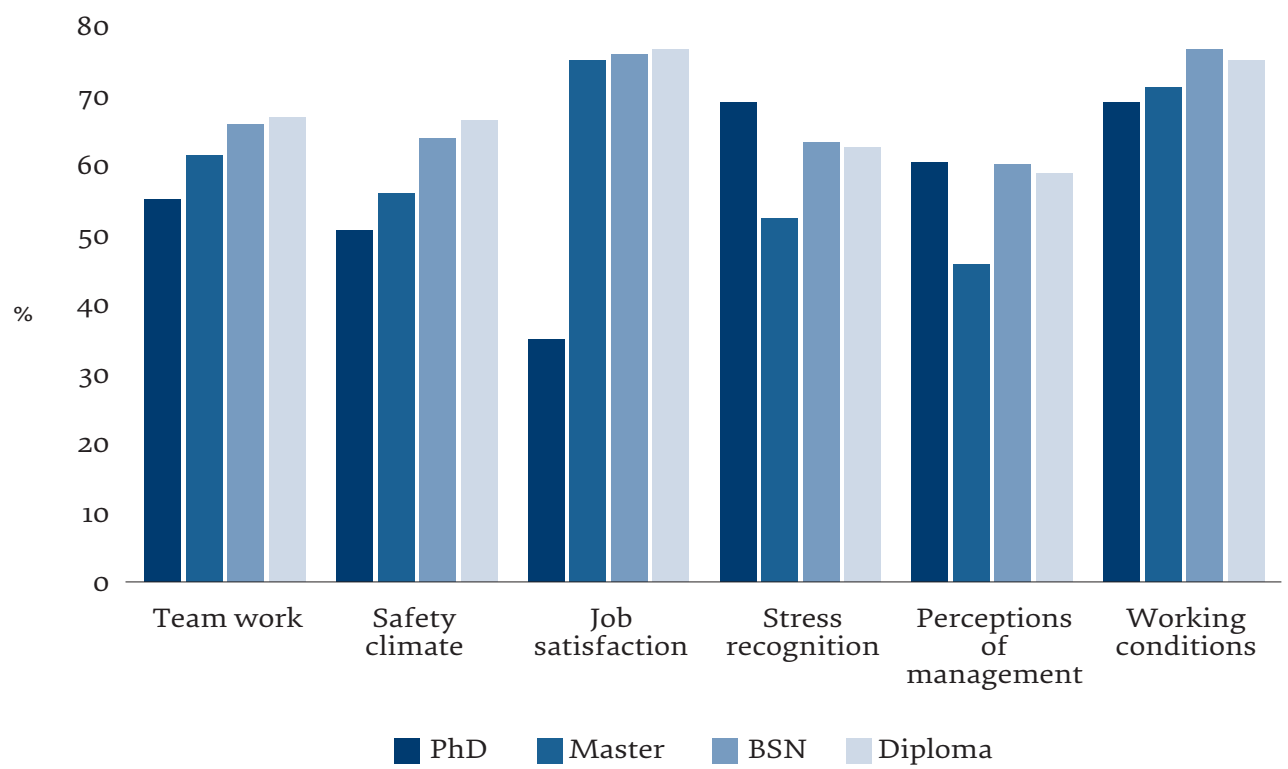

compromise patient safety.

In assessing working conditions, almost two thirds of participants stated that the health centre did a good job of training new personnel; all necessary information for diagnostic and therapeutic decisions was routinely available to them, and trainees in their discipline were adequately supervised.

\section{Discussion}

The present study is the first to document patient safety culture attitudes among nurses in accredited primary healthcare centres in Jordan. The SAQ showed that job satisfaction and working conditions were the domains with values $>75 \%$ for positive safety attitude among nurses, while stress recognition and perception of management received the lowest scores. These findings are similar to a study about the attitude of academic ambulatory nurses toward patient safety culture in Saudi Arabia. Nurses had the highest level (88\%) of positive attitudes toward their job; the second highest positive attitude $(77 \%$ ) was toward working conditions; and stress recognition and perception of management received lower scores (24). This may be explained by the resemblance between the two neighbouring Arab countries, as well as the presence of many Jordanian nurses working in Saudi Arabia.

Our results are also similar to the findings of a study carried out in Egypt, where job satisfaction had the highest mean scores $(>75 \%)$, while perception of management received the lowest $(\leq 75 \%)(25)$. Furthermore, a negative perception of stress recognition was found in a study of patient safety culture among Egyptian healthcare employees (26), and similar findings have been reported in other studies $(27,28)$. In Palestine, job satisfaction was ranked the highest safety attitude domain (27). In Brazil, the job satisfaction and work conditions domains were perceived by professionals as positive for safety attitude

(28). In Ribeirão Preto City, Brazil, work satisfaction was the only domain with values $>75 \%$ (29). This might be due to a higher degree of attachment to their own work place among nurses and more experienced employees (30). The findings of the Brazilian study (29) demonstrated that only the job satisfaction domain is evidenced by the positive experiences with work; it is perceived by professionals as positive for an attitude of safety in the workplace. The domains that stand out with lower scores are perception of hospital management, perception of stress and perception of unit management (28). The positivity toward job satisfaction indicates that participants are reasonably satisfied with their job and will be positively involved in accepting and implementing future quality improvement initiatives. In addition, the importance of job satisfaction cannot be ignored because it is imperative, can improve staff enthusiasm, and stimulate productivity as well as quality of work (31). Conversely, a study conducted in Norway indicated that the overall mean score was $79.1 \%$ for teamwork climate and $72.3 \%$ for safety climate (32). Participants showed positive perceptions of 5 domains: job satisfaction, teamwork climate, working conditions, management and safety climate compared to our study, which showed positive perception only for 2 domains: job satisfaction and working conditions. This means that the overall perception for all domains was $<50 \%$, which is in line with findings of Elsous et al. (31).

Our study found that the highest positive safety score $(78.10 \%)$ toward job satisfaction was among nurses with $>20$ years' of experience, while the highest positive score toward working conditions was among nurses with 1115 years of experience. This could be because, as people become more experienced, they become more aware of the safety practices undertaken in their institutions (12). It might be due to the belief that managers are more satisfied with older nurses' support because older nurses are more knowledgeable, display more positive attitudes 
Table 3 Distribution of answers of accredited primary health-care centre nurses per item

\begin{tabular}{|c|c|c|c|c|c|c|}
\hline \multirow[t]{2}{*}{ Questions } & \multicolumn{2}{|c|}{$\begin{array}{l}\text { Disagree and } \\
\text { strongly disagree }\end{array}$} & \multicolumn{2}{|c|}{ Neutral } & \multicolumn{2}{|c|}{$\begin{array}{c}\text { Agree and strongly } \\
\text { agree }\end{array}$} \\
\hline & $\mathbf{n}$ & $\%$ & n & $\%$ & n & $\%$ \\
\hline 1. Nurse input is well received in this clinical area & 69 & 10.7 & 64 & 9.9 & 500 & 77.6 \\
\hline $\begin{array}{l}\text { 2. } \mathrm{R}^{\mathrm{a}} \text {. In this clinical area, it is difficult to speak up if I perceive a } \\
\text { problem with patient care. }\end{array}$ & 241 & 37.4 & 126 & 19.6 & 252 & 39.1 \\
\hline 3. Disagreements in this clinical area are resolved appropriately & 97 & 15.1 & 98 & 15.2 & 426 & 66.1 \\
\hline 4. I have the support I need from other personnel to care for patients & 93 & 14.4 & 49 & 7.6 & 489 & 75.9 \\
\hline $\begin{array}{l}\text { 5. It is easy for personnel here to ask questions when there is some- } \\
\text { thing that they do not understand }\end{array}$ & 79 & 12.3 & 56 & 8.7 & 501 & 77.8 \\
\hline $\begin{array}{l}\text { 6. The physicians and nurses here work together as a well-coordi- } \\
\text { nated team }\end{array}$ & 57 & 8.9 & 62 & 9.6 & 518 & 80.4 \\
\hline 7. I would feel safe being treated here as a patient & 73 & 11.3 & 83 & 12.9 & 477 & 74.1 \\
\hline 8. Medical errors are handled appropriately in this clinical area & 73 & 11.3 & 81 & 12.6 & 475 & 73.8 \\
\hline $\begin{array}{l}\text { 9. I know the proper channels to direct questions regarding patient } \\
\text { safety in this clinical area }\end{array}$ & 73 & 11.3 & 97 & 15.1 & 444 & 68.9 \\
\hline 10. I receive appropriate feedback about my performance & 113 & 17.5 & 97 & 15.1 & 408 & 63.4 \\
\hline 11. $R^{\mathrm{a}}$. In this clinical area, it is difficult to discuss errors & 256 & 39.8 & 133 & 20.7 & 234 & 36.3 \\
\hline $\begin{array}{l}\text { 12. I am encouraged by my colleagues to report any patient safety } \\
\text { concerns I may have }\end{array}$ & 78 & 12.1 & 99 & 15.4 & 442 & 68.6 \\
\hline $\begin{array}{l}\text { 13. The culture in this clinical area makes it easy to learn from the } \\
\text { errors of others }\end{array}$ & 63 & 9.8 & 72 & 11.2 & 490 & 76.1 \\
\hline $\begin{array}{l}\text { 14. My suggestions about safety would be acted upon if I expressed } \\
\text { them to management }\end{array}$ & 102 & 15.8 & 152 & 23.6 & 361 & 56.1 \\
\hline 15. I like my job & 92 & 14.3 & 48 & 7.5 & 496 & 77 \\
\hline 16. Working here is like being part of a large family & 84 & 13 & 82 & 12.7 & 465 & 72.2 \\
\hline 17. This is a good place to work & 89 & 13.8 & 75 & 11.6 & 475 & 73.8 \\
\hline 18. I am proud to work in this clinical area & 70 & 10.9 & 78 & 12.1 & 485 & $75 \cdot 3$ \\
\hline 19. Morale in this clinical area is high & 79 & 12.3 & 84 & 13 & 470 & 73 \\
\hline $\begin{array}{l}\text { 20. When my workload becomes excessive, my performance is im- } \\
\text { paired }\end{array}$ & 195 & 30.3 & 73 & 11.3 & 364 & 56.5 \\
\hline 21. I am less effective at work when fatigued & 137 & 21.3 & 53 & 8.2 & 439 & 68.2 \\
\hline 22. I am more likely to make errors in tense or hostile situations & 173 & 26.9 & 73 & 11.3 & 382 & $59 \cdot 3$ \\
\hline 23. Fatigue impairs my performance during emergency situations & 186 & 28.9 & 61 & 9.5 & 380 & 59 \\
\hline 24. Management supports my daily efforts & 152 & 23.6 & 152 & 23.6 & 303 & 47 \\
\hline 25. Management does not knowingly compromise patient safety & 99 & 15.4 & 116 & 18 & 403 & 62.6 \\
\hline 26. Management is doing a good job & 110 & 17.1 & 134 & 20.8 & 381 & 59.2 \\
\hline 27. Problem personnel are dealt with constructively by our: & 127 & 19.7 & 116 & 18 & 376 & 58.4 \\
\hline 28. I get adequate, timely info about events that might affect my work: & 131 & 20.3 & 110 & 17.1 & 372 & 57.8 \\
\hline $\begin{array}{l}\text { 29. The levels of staffing in this clinical area are sufficient to handle } \\
\text { the number of patients }\end{array}$ & 223 & 34.6 & 54 & 8.4 & 342 & 53.1 \\
\hline 30. This health centre does a good job of training new personnel & 123 & 19.1 & 81 & 12.6 & 428 & 66.5 \\
\hline $\begin{array}{l}\text { 31. All the necessary information for diagnostic and therapeutic deci- } \\
\text { sions is routinely available to me }\end{array}$ & 85 & 13.2 & 116 & 18 & 431 & 66.9 \\
\hline 32. Trainees in my discipline are adequately supervised & 121 & 18.8 & 89 & 13.8 & 426 & 66.1 \\
\hline 33. I experience good collaboration with nurses in this clinical area & 49 & 7.6 & 52 & 8.1 & 536 & 83.2 \\
\hline $\begin{array}{l}\text { 34. I experience good collaboration with staff physicians in this clin- } \\
\text { ical area }\end{array}$ & 47 & 7.3 & 53 & 8.2 & 539 & 83.7 \\
\hline $\begin{array}{l}\text { 35. I experience good collaboration with pharmacists in this clinical } \\
\text { area }\end{array}$ & 62 & 9.6 & 71 & 11 & 503 & 78.1 \\
\hline $\begin{array}{l}\text { 36. Ra. Communication breakdowns that lead to delays in delivery of } \\
\text { care are common. }\end{array}$ & 264 & 41 & 98 & 15.2 & 267 & 41.5 \\
\hline
\end{tabular}

Reverse items 
to safety and are possibly more committed to work than younger workers are (6).

On teamwork climate, $39.1 \%$ of nurses claimed that it was difficult to speak up when they perceived a problem related to patient care. A total of $76.1 \%$ affirmed that the culture in this clinical area made it easy to learn from the errors of others; $56.1 \%$ answered that suggestions about safety would be acted upon if they were expressed to management; and $63.4 \%$ stated that they received appropriate feedback about performance. However, a study in Brazil showed corresponding values of $62 \%, 49 \%$, $57 \%$ and $45 \%$, respectively(29).

Our study showed a positive score attributed to job satisfaction. This could possibly be due to the decision of the Council of Ministers and Ministry of Health in Jordan, according to which, the proportion of incentives for nurses in the Ministry has been increased from 20 to $25 \%$. The increase has taken in all categories, including legal (registered) nurses, participants and assistants. In addition, work is currently underway to improve both mobility allowance and acquisition allowance on a fair basis that takes into account the provisions of the system for travel.

Based on this study, the safety culture at these primary health care centres services (i.e., the negative score was $64.8 \%$ ) definitely needs to be improved. Therefore, patient safety issues should be addressed more systematically in primary health care. By identifying areas of weaknesses and thus motivating immediate interventions, the risk of medical errors and negative patient outcomes could be reduced to the minimum (30).

The importance of developing patient safety programmes aimed at giving greater attention to the patient safety culture in primary healthcare centres, as in hospitals, is one immediate implication from our study. In addition to optimizing the existing patient safety culture, these programmes can help improve the perception of nurses in these settings. An understanding of nurses' perceptions regarding adverse events is therefore essential for the implementation of patient safety protocols and strategies to manage and improve nursing care. However, there is still a need to know more about primary healthcare nurses' perceptions regarding patient safety.

\section{Recommendations}

- Information technology should be utilized to improve patient safety in primary healthcare centres (e.g. automated drug order or entry systems).

- Initial education and continuous learning programmes aimed at healthcare providers should integrate patient safety topics into the educational curricula.

- Policy-makers and health planners should build a patient-safe infrastructure and should promote organizational culture in primary healthcare centres.

- Nurses, patients and families, as well as leaders and managers should all participate in the strategies that are developed by policy-makers and health planners.

- It is finally recommended to conduct further surveys and studies that contribute to quality improvement associated with nurses' perception of safety culture in primary healthcare centres.

\section{Conclusion}

Jordanian primary healthcare nurses perceive their health centres as places that need more effort to improve patient safety culture. Ongoing patient safety improvement programmes, periodic safety culture measurements involving key stakeholders, planning safety improvements and raising nurses' awareness about patient safety are recommended.

Funding: None.

Competing interests: None declared.

\section{La culture de la sécurité des patients dans les centres de soins de santé primaires en Jordanie du point de vue des personnels infirmiers : étude transversale}

\section{Résumé}

Contexte : La sécurité des patients constitue une préoccupation majeure, tant dans les hôpitaux que dans les établissements de soins primaires. Selon l'Association médicale de Jordanie, tous les centres de soins devraient s'efforcer d'améliorer la sécurité des patients en renforçant la culture institutionnelle, comme c'est le cas dans les hôpitaux. En Jordanie, aucune étude complète n'a encore été réalisée sur la culture de la sécurité des patients dans les centres de soins de santé primaires.

Objectifs : Évaluer les attitudes des personnels infirmiers à l'égard de la sécurité des patients dans les centres de soins de santé primaires en Jordanie.

Méthodes : Une étude transversale descriptive a été menée en 2017. Des données ont été recueillies auprès de 644 membres du personnel infirmier travaillant dans les 91 centres de soins de santé primaires accrédités en Jordanie, en utilisant la version courte (36 items) du questionnaire sur les attitudes à l'égard de la sécurité.

Résultats : Le taux moyen de réponses positives dans les six domaines de la culture de la sécurité était compris entre $58,54 \%$ et 75,63\%. Le taux le plus élevé portait sur la satisfaction au travail et le plus faible concernait la perception de l'administration. 
Conclusions : Selon les personnels infirmiers, les points à améliorer sont les suivants : esprit d'équipe, climat de sécurité, reconnaissance du stress et perception de l'administration. Les personnels infirmiers qui travaillent dans des services de soins de santé primaires en Jordanie estiment que des efforts supplémentaires doivent être déployés dans leurs établissements pour améliorer la culture de la sécurité.

\section{ثقافة سلامة المرضى في مر اكز الرعاية الصحية الأولية الأردنية كما تتصورها طواقم التمريض: دراسة مقطعية عبد الله خمايسه، ديالا الطو البه، كامل العجلوني}

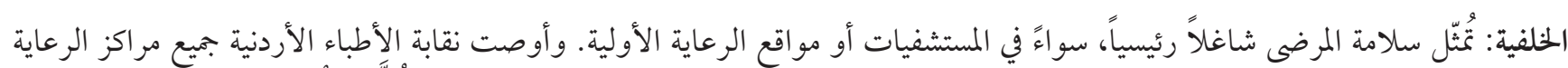

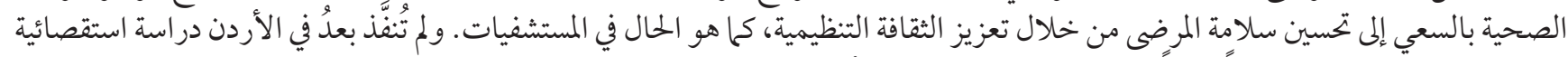
حول ثقافة سلامة المرضى تنفيذاً كاملاً فُ في مر اكز الرعاية الصحية الأولية.

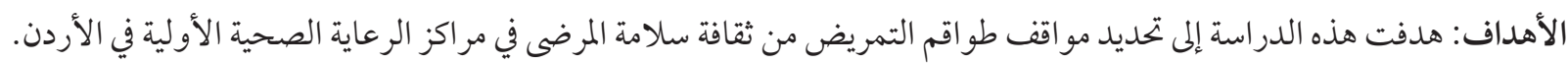

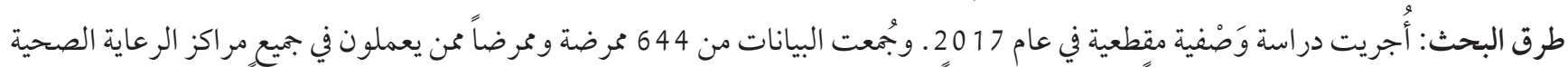

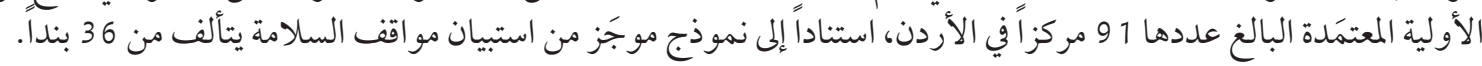

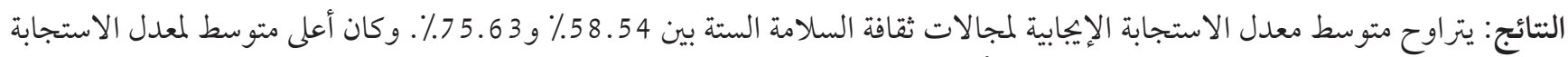

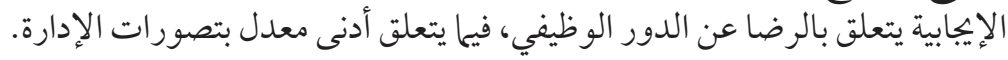

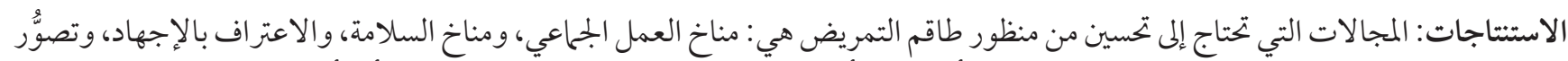

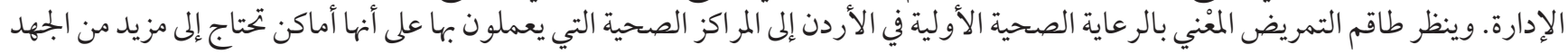
لتعزيز ثقافة السلامة.

\section{References}

1. Transitions of care: technical series on safer primary care. Geneva; World Health Organization; 2016 (http://apps.who.int/iris/bitn stream/handle/10665/252272/9789241511599-eng.pdf;jsessionid=2893E2FC34DDF6F27C452A7CADB84611?sequence=1, accessed 27 March 2020).

2. Al-Doseri FA. Assessment of patient safety culture among health care providers in primary health care settings in Kuwait [thesis]. Cairo University; 2012.

3. Rao MV, Thota D, Srinivas P. A study to assess patient safety culture amongst a category of hospital staff of a teaching hospital. IOSR J Dent Med Sci. 2014 Mar;13(3):16-22.

4. Ghobashi MM, El-ragehy HAG, Ibrahim HM, Al-Doseri FA. Assessment of patient safety culture in primary health care settings in Kuwait. Epidemiol Biostat Public Health. 2014;11(3). https://doi.org/10.2427/9101

5. Wallis, K. and S. Dovey, Assessing patient safety culture in New Zealand primary care: a pilot study using a modified Manchester Patient Safety Framework in Dunedin general practices. J Prim Health Care. 2011 Mar 1;3(1):35-40. PMID:21359259

6. Abdou HA, Saber KM. A baseline assessment of patient safety culture among nurses at student university hospital. World J Med Sci. 2011;6(1):17-26.

7. Elmontsri M, Almashrafi A, Banarsee R, Majeed A. Status of patient safety culture in Arab countries: a systematic review. BMJ Open. 2017 Feb 24;7(2):e013487. http://dx.doi.org/10.1136/bmjopen-2016-013487 PMID:28237956

8. Bodur S, Filiz E. A survey on patient safety culture in primary healthcare services in Turkey. Int J Qual Health Care. 2009 Oct;21(5):348-55. http://dx.doi.org/10.1093/intqhc/mzp035 PMID:19700779

9. Tabrizchi N, Sedaghat M. The first study of patient safety culture in Iranian primary health centers. Acta Med Iran. 2012;50(7):505-10. PMID:22930384

10. Jones KJ, Skinner A, Xu L, Sun J, Mueller K. The AHRQ hospital survey on patient safety culture: a tool to plan and evaluate patient safety programs. In: Henriksen K, Battles JB, Keyes MA, et al., editors. Advances in patient safety: new directions and alternative approaches (Vol. 2: culture and redesign). Rockville (MD): Agency for Healthcare Research and Quality (US); 2008.

11. Relihan E, Glynn S, Daly D, Silke B, Ryder S. Measuring and benchmarking safety culture: application of the safety attitudes questionnaire to an acute medical admissions unit. Ir J Med Sci. 2009 Dec;178(4):433-9. http://dx.doi.org/10.1007/s11845-0090352-2 PMID:19437091

12. Theodosios S. The development of patient safety culture. Health Sci J. 2012 Apr-Jun;6(2):2-1-11. https://www.hsj.gr/medicine/ the-development-of-patient-safety-culture.pdf 
13. Webair HH, Al-Assani SS, Al-Haddad RH, Al-Shaeeb WH, Bin Selm MA, Alyamani AS. Assessment of patient safety culture in primary care setting, Al-Mukala, Yemen. BMC Fam Pract. 2015 Oct 13;16:136. http://dx.doi.org/10.1186/s12875-015-0355-1 PMID:26463229

14. Astier-Peña MP, Torijano-Casalengua ML, Olivera-Cañadas G, Silvestre-Busto C, Agra-Varela Y, Maderuelo-Fernández JÁ. Are Spanish primary care professionals aware of patient safety? Eur J Public Health. 2015 Oct;25(5):781-7. http://dx.doi.org/10.1093/ eurpub/ckv066 PMID:25842381

15. de Mesquita KO, Chagas da Silva LC, Lira RCM, Freitas XASL, Lira GV. Patient safety in primary health care: an integrative review. Cogitare Enferm. 2016 Apr-Jun;21(2):01-8.

16. Ammouri AA, Tailakh AK, Muliira JK, Geethakrishnan R, Al Kindi SN. Patient safety culture among nurses. Int Nurs Rev. 2015 Mar;62(1):102-10. http://dx.doi.org/10.1111/inr.12159 PMID:25495946

17. Balamurugan E, Flower JL. A study on patient safety culture among nurses in a tertiary care hospital of Puducherry. Int J Basic Appl Med Sci. 2014 May-Aug;4(2):93-8

18. Singh G, Singh R, Thomas EJ, Fish R, Kee R, McLean-Plunkett E et al. Measuring safety climate in primary care offices. In: Henriksen K, Battles JB, Keyes MA, Grady ML, editors. Advances in patient safety: new directions and alternative approaches (Vol. 2: culture and redesign). Rockville, MD: Agency for Healthcare Research and Quality (US); 2008.

19. Verbakel NJ, Langelaan M, Verheij TJ, Wagner C, Zwart DL. Improving patient safety culture in primary care: a systematic review. J Patient Saf. 2016 Sep;12(3):152-8. http://dx.doi.org/10.1097/PTS.0000000000000075 PMID:24647271

20. Nazer, L.H. and H. Tuffaha, Health care and pharmacy practice in Jordan. Can J Hosp Pharm. 2017 Mar-Apr;70(2):150-5. PMID:28487583

21. The High Health Council. The National Strategy for Health Sector in Jordan 2015-2019. The Hashemite Kingdom of Jordan. The High Health Council; 2015 (http://www.hhc.gov.jo/uploadedimages/The\%20National\%20Strategy\%20for\%20Health\%20Sector\%20 in\%20Jordan\%202015-2019.pdf, accessed 31 March 2020).

22. Hayajneh YA, AbuAlRub RF, Almakhzoomy IK. Adverse events in Jordanian hospitals: types and causes. Int J Nurs Pract. 2010 Aug;16(4):374-80. http://dx.doi.org/10.1111/j.1440-172X.2010.01854.x PMID:20649669

23. Paese F, Marcon dal Sasso GT. Cultura da segurança do paciente na atenção primária à saúde. Texto Contexto Enferm 2013 AprJun;22(2):302-10 (in Portuguese).

24. Saraiva DMRF, Almeida A. Validation of the Safety Attitudes Questionnaire-Short Form 2006 to Portugal. Int J Nurs. 2015 Jun;2:103-12. http://dx.doi.org/10.15640/ijn.v2n1a11

25. Zakari NMA. Attitude of academic ambulatory nurses toward patient safety culture in Saudi Arabia. Life Sci J. 2011;8(3):230-7.

26. El-Gendi S, Seung H, Abdelsamie SM, Feemster AA. Assessment of patient safety culture among Egyptian healthcare employees. Med Saf Glob Health, 2017;6:2. http://dx.doi.org/10.4172/2574-0407/1000134

27. Elsous A, Akbari Sari A, AlJeesh Y, Radwan M. Nursing perceptions of patient safety climate in the Gaza Strip, Palestine. Int Nurs Rev. 2017 Sep;64(3):446-54. http://dx.doi.org/10.1111/inr.12351 PMID:28102544

28. Tondo JCA, Guirardello EB. Perception of nursing professionals on patient safety culture. Rev Bras Enferm. 2017 NovDec;70(6):1284-90. http://dx.doi.org/10.1590/0034-7167-2016-0010 PMID:29160491

29. Rigobello CG, Lima de Carvalho REF, De Bortoli Cassiani SH, Galon T, Capucho HC, Nogueira de Deus N. The climate of patient safety: perception of nursing professionals. Acta Paul Enferm 2012;25(5):728-35 (in Portuguese).

30. Bondevik GT, Hofoss D, Hansen EH, Deilkås EC. Patient safety culture in Norwegian primary care: a study in out-of-hours casualty clinics and GP practices. Scand J Prim Health Care. 2014 Sep;32(3):132-8. http://dx.doi.org/10.3109/02813432.2014.962791 PMID:25263763

31. Elsous A, Akbari Sari A, Rashidian A, Aljeesh Y, Radwan M, AbuZaydeh H. A cross-sectional study to assess the patient safety culture in the Palestinian hospitals: a baseline assessment for quality improvement. JRSM Open. 2016 Dec 1;7(12). http://dx.doi. org/2054270416675235 PMID:27928510

32. Olsen RM, Bjerkan J. Patient safety culture in Norwegian home health nursing: a cross-sectional study of healthcare provider's perceptions of the teamwork and safety climates. Saf Health. 2017;3:15. https://doi.org/10.1186/s40886-017-0066-5 